\title{
A life-cycle model of unemployment and disability insurance
}

\author{
Sagiri Kitao*
}

November 27, 2012

\begin{abstract}
The paper builds a life-cycle model of heterogeneous agents with search frictions, in which individuals choose a sequence of saving and labor supply faced with uncertainty in longevity, employment, health status and medical expenditures. Unemployed individuals decide search intensity and whether to apply for disability insurance (DI) benefits if eligible. We investigate, first, the effects of cash and Medicare benefits of the DI system on the life-cycle pattern of employment. Without in-kind benefits through Medicare, the DI coverage could fall by $30 \%$. Second, the impact of a change in labor market conditions and roles of the DI are studied. A rise in exogenous job separation rates or a fall in job finding rates by $20 \%$ each can lead to a drop in employment rate by 1.7 and 2.1 percentage points, respectively. A model without the DI could underestimate the effect on employment by more than $30 \%$.
\end{abstract}

Keywords: Disability insurance, labor force participation, life-cycle, Medicare, unemployment insurance.

J.E.L. classification codes: E2, E6, J2, J6

*Hunter College, CUNY. E-mail: sagiri.kitao@gmail.com. 


\section{Introduction}

According to the Social Security Administration (SSA), more than 8 million individuals received disability insurance (DI) benefits in 2011. ${ }^{1}$ The likelihood of receiving the DI benefits rises in age and more than 1 in 7 individuals at age 60-64 are DI recipients. Most, if not all, DI recipients are out of labor force and constitute a large fraction of non-employed individuals before the retirement age. To understand the pattern of labor force participation over the life-cycle, it is important to identify the roles played by the DI in the context of risks individuals face and work incentives associated with the public insurance program.

This paper builds a structural life-cycle model to study individuals' consumption, saving and labor supply decisions focusing on the roles of the disability insurance. Understanding the effects of publicly provided insurance requires a model that captures various important risks that affect individuals over the life-cycle and insurance opportunities available to them, both privately and through the government. In our model, individuals choose a sequence of consumption, saving and labor supply, while facing risks in longevity, employment, health status and medical expenditures. Markets are incomplete without state-contingent assets to insure away the risks, but individuals can engage in precautionary savings and accumulate riskless assets. The government provides partial insurance through transfer programs including unemployment insurance, disability insurance, welfare programs and social security. Individuals optimally choose inter and intra-temporal allocations given the incentives embedded in the transfer system.

Employed individuals in our model can be separated from a job either exogenously or endogenously by quitting. Unemployed individuals choose search intensity, which affects the likelihood of finding a job. Once an individual is unemployed for a given period, he can apply for the DI benefits if eligibility conditions are met. Individuals who have received the DI benefits for two years become automatically entitled to Medicare benefits. Upon reaching the retirement age, individuals will start to receive both social security benefits and the Medicare coverage.

The model is calibrated to key features of the U.S. economy using micro database including the Medical Expenditure Panel Survey (MEPS) and the Panel Study of Income Dynamics (PSID). We use the model to address two questions. First, how do the cash and in-kind Medicare benefits of the DI system affect employment status over the lifecycle? Second, how do exogenous changes in labor market conditions affect employment distribution and what are the roles of the DI?

Experiments show that both cash and in-kind benefits through Medicare are important in explaining patterns of employment and DI coverage. Eliminating the Medicare benefit for DI recipients can lower the DI coverage by $30 \%$ and the employment rate can be higher by 1.5 percentage points. The DI coverage is sensitive to the level of cash benefits. A $20 \%$ reduction of the benefits, for example, can reduce the coverage by more than one-third and raise the employment rate by 1.7 percentage points.

\footnotetext{
${ }^{1}$ The figure is for disabled workers only and recipients of the federal Social Security Disability Insurance (SSDI), based on the SSA's Annual Statistical Supplement 2011. The total number including disabled wodow(er)s and children is 10.3 million in 2010, according to the Annual Statistical Supplement to the Social Security Bulletin, 2011.
} 
Unfavorable labor market conditions raise the number of DI recipients and reduces employment by more than in a model without the DI system. A $20 \%$ increase in the exogenous job separation rate would lead to a 1.7 percentage point decline in our benchmark model, but it would be only 1.1 percentage points without the DI. Similar difference is found when job finding rates decline.

Our model is an extension of incomplete market models pioneered by Bewley (1986), Huggett (1993) and Aiyagari (1994) in a life-cycle framework of Auerbach and Kotlikoff (1987), augmented with labor market frictions, stochastic health and medical expenditures and disability insurance. There have been recent papers that incorporate health shocks over the life cycle in this class of models to evaluate roles of health status, medical expenditures and insurance arrangements. French (2005) estimates a life-cycle model of employment with stochastic health status and explains the pattern of job exits at old ages and the roles of social security benefit rules. De Nardi et al. (2010) build a model of retirees to study the effect of longevity risk and health expenditure uncertainty on the savings. French and Jones (2011) analyze labor supply and retirement behavior of old-age individuals, focusing on the roles of employer-based health insurance, Medicare and social security. Kopecky and Koreshkova (2009) use a life-cycle model to analyze the effect of nursing home expenses and Medicaid. Imrohoroğlu and Kitao (2012), Attanasio et al. (2011) and Jeske and Kitao (2009) analyze policies on social security, Medicare, employer-based health insurance, respectively, in a model with health and medical expenditure uncertainties. Hsu (2012) studies the role of employer based health insurance on the distribution of precautionary savings.

A few recent papers added disability insurance in a structural life-cycle model. Low et al. (2010) build a dynamic model of consumption, labor supply and job mobility, estimate employment and productivity risks and quantify precautionary responses in labor supply and job mobilities. Low and Pistaferri (2011) add disability health shocks to Low et al. (2010) and study the impact of changes in the details of the DI program. Benitez-Sílva et al. (2011) analyze the effect of a policy that would encourage the DI recipients to return to work through tax incentives. The three papers abstract from medical expenditures and Medicare benefits are not included in the DI system. To the best of my knowledge, this is the first paper in the line of the literature that builds a life-cycle model of consumption-saving and employment with medical expenditures and health uncertainty, augmented with endogenous DI coverage that consists of cash and Medicare benefits.

The rest of the paper is organized as follows. The model economy is described in Section 2. The calibration of the model is discussed in Section 3. Section 4 presents the quantitative findings of the paper. Section 5 concludes.

\section{Model}

This section presents the model. 


\subsection{Demographics, preferences and labor market}

There is a continuum of individuals with stochastic life-spans. Individuals go through a finite number of age groups stochastically, indexed by $j=1,2, \cdots, J$. The probability of transitioning from age $j$ to $j+1$ is denoted by $\phi_{j}$. Individuals face a mortality risk and the probability of surviving until the next period is denoted by $\rho_{j}$ and depends on the age of an individual. Bequests are accidental and they are transferred to the entire population in a lump-sum manner, denoted as $x$. The size of new entrants to the economy grows at rate $n$.

Preferences are time-separable and individuals derive utility from consumption $c$ and leisure $l$ according to the function $u(c, l)$. Future utility is discounted by the subjective discount factor $\beta$. Assets that are not consumed are rented out and earn the market interest $r$. Each individual has a unit of lost leisure time, which can be spent for leisure, market work or job search. Individuals who participate in the labor market incur disutility of $B_{j, h}^{e}$ measured in terms of disposable time, which can depend on age $j$ and health status $h$. Unemployed individuals choose a search intensity $s \in[0,1]$, which costs disutility $B_{j, h}^{s}(s)$ similarly to the participation disutility. With the search effort $s$, an unemployed individual finds a job offer with probability $\pi^{s}(s)$, which he chooses to accept or reject.

Employed individuals earn labor income, that depends on each individual's skill level $g$ and the market wage $w$. Skills accumulate stochastically while being employed and decumulate while being unemployed, within the range of $[g, \bar{g}]$. An employed individual of age $j$ with the current skill level of $g$ faces transition probabilities $\Gamma_{j}^{E}\left(g, g^{\prime}\right)$ that his skills will be $g^{\prime}$ next period. A non-working individual's skills evolve according to the transition probability of $\Gamma_{j}^{N}\left(g, g^{\prime}\right)$. New entrants start a career with the skill level $\underline{g}$. Employment can be terminated exogenously with probability $\sigma$.

\subsection{Health, medical expenditures and health insurance}

Health status of an individual evolves stochastically. An individual of age $j$ with the current health status $h$ faces a probability $\pi_{j}^{h}\left(h, h^{\prime}\right)$ that his health status will be $h^{\prime}$ in the following period.

In the model health affects the distribution of medical expenditures, in addition to the disutility of labor participation and search effort and the likelihood of facing a disability shock as we discuss below. Individuals of age $j$ and health status $h$ face gross medical expenditure $m(j, h)$, which is a draw from a distribution $\Pi^{m}(m ; j, h)$.

We assume that employed individuals have access to group health insurance and have a fraction $q_{H I}$ of expenditures covered by the insurance in exchange for a premium of $p_{H I}$, which is subtracted from the wage bill. ${ }^{2}$ We assume that the premium is set so that there is no profit earned by a provider of group health insurance.

\footnotetext{
${ }^{2}$ We assume that all employers offer health insurance and all employees are covered by group health insurance at work. See Jeske and Kitao (2009) for a dynamic equilibrium model where insurance offers arrive stochastically and the insurance take-up is an endogenous decision. We abstract from the complex heterogeneity in private health insurance access and coverage for simplicity and it is an issue to explore in future research.
} 


\subsection{The government}

Unemployment insurance: Individuals whose jobs are terminated exogenously are entitled to unemployment benefits for up to the maximum duration of $\overline{d_{U}}$ periods. ${ }^{3}$ The benefits are determined as a function of an individual's past earnings $e$ and denoted as $b_{U}(e)$. Benefits are capped above at $\overline{b_{U}}$.

Disability Insurance (DI): Unemployed individuals can apply for the disability insurance provided that eligibility conditions are met. The Social Security Administration (SSA) require that individuals wait for at least five months before receiving the DI benefits. ${ }^{4}$ We assume that individuals can apply for the DI after the second period of unemployment (after the fourth month). Unemployed individuals of age $j$ with health status $h$ are assumed to face a "disability shock," which arrives with probability $\theta_{j, h}$. Individuals receiving the disability shock are able to apply for the DI benefit. Applications are accepted with probability $\pi_{D}$ and benefits start to be paid in the following period.

Successful applicants will receive the DI benefits $b_{D}(e)$, which depend on the past earnings $e$. After receiving the DI benefits for two years, individuals automatically become entitled to Medicare benefits. Both cash and Medicare benefits continue until the recipients either die or reach the retirement age, when the DI benefits convert to social security benefits and the same amount of benefits continue to be paid.

Social insurance: The government provides a means-tested transfer denoted as $b_{S I}$ in case disposable assets of an individual at the beginning of the period fall below the threshold level of $\underline{a}$. The transfer enables individuals to consume at least $\underline{a}$ in each period.

Social security and Medicare: Individuals at or above the retirement age $j_{R}$ receive social security benefits $s s(e)$. They are also enrolled in Medicare, which pays a fraction $q_{M}$ of medical expenditures of covered individuals. The same coverage rate applies to the DI recipients with Medicare eligibility.

Government expenditures and taxes: The government imposes taxes on labor income at rate $\tau^{l}$, consumption at $\tau^{c}$ and capital income at rate $\tau^{k}$. The government expenditures other than the spending on the programs explained above are denoted as $G$.

\subsection{Individual problem}

Individuals in the model are heterogeneous in several dimensions and we group them into four groups, employed $(E)$, unemployed $(U)$, DI recipients $(D)$ and retirees $(R)$ and define value functions for each group. The state vector of an employed individuals is given as

\footnotetext{
${ }^{3}$ The eligibility of unemployment insurance requires that recipients must be actively searching for work and accept suitable work. We assume, however, that the monitoring of such requirements is less than perfect and individuals can maintain the unemployment insurance for the maximum periods even if the search effort is minimal or zero, or job offers are rejected.

${ }^{4}$ See http://www.ssa.gov/disability/ for more details about eligibility and application procedures.
} 
$S_{E}=(j, a, g, h)$, where $j$ represents age, $a$ assets carried over from the previous period, $g$ skills and $h$ health status.

Unemployed individuals' state vector is $S_{U}=\left(j, a, g, h, e, d_{U}, i_{U}\right)$. e represents past earnings and affects the amount of unemployment insurance benefits as well as disability insurance and social securities. $d_{U}$ denotes the elapsed duration of unemployment. The indicator $i_{U} \in\{0,1\}$ indicates whether the individual currently receives unemployment insurance benefits or not. The state vector of a DI recipient is $S_{D}=\left(j, a, h, e, i_{M}\right)$, where an indicator $i_{M} \in\{0,1\}$ represents eligibility to receive Medicare benefits. Individuals retire at the mandatory retirement age $j_{R}$ and start to receive social security benefits. A retiree's state vector is $S_{R}=(j, a, h, e)$.

The timing of events is as follows. At the beginning of the period individuals choose the level of consumption given the state vector. The government gives a social insurance transfer to individuals if assets fall below the threshold level. Unemployed individuals learn about the disability shock and also choose the search effort $s$ and whether to apply for the DI benefits if eligible. The indicator $i_{D}$ takes a value 1 if an unemployed individual applies for the DI benefits and 0 otherwise. Individuals consume and rent remaining assets to earn interest and employed workers receive the wage. Medical expenditures are realized and out-of-pocket expenses are paid.

At the end of the period, health status $h^{\prime}$ and skills $g^{\prime}$ for the next period are realized and individuals learn about demographic shocks, that is, whether they survive to the next period and if they move to the next age group. Employed individuals face a probability $\sigma$ that the job is terminated exogenously. Individuals that do not face an exogenous termination can choose whether to quit the job or remain employed. Unemployment individuals find a job offer with probability $\pi^{s}(s)$, which they decide to accept or reject. If an unemployed individual applied for the DI, he learns the outcome of the application before the start of the next period.

The value functions and budget constraints of the employed, unemployed, DI recipients and retirees are presented below. ${ }^{5}$ The rented capital $k$ and the social insurance transfer $b_{S I}$ are defined as

$$
\begin{aligned}
k & =a-\left(1+\tau^{c}\right) c+b_{S I}, \quad k \geq 0 \\
b_{S I} & =\max \{0, \underline{a}-a\}
\end{aligned}
$$

Equations (1) and (2) apply for the problem of all four types of individuals.

Employed individuals: Employed individuals choose consumption at the beginning of the period, and conditional on no exogenous separation, they also decide whether to remain employed or quit the job and become unemployed.

\footnotetext{
${ }^{5}$ Note that with probability $\phi_{j}$ individuals in the age group $j=j_{R}-1$, right before the retirement, will reach the retirement age and become a retiree next period. The value function will then be that of a retiree, $V^{R}\left(j+1, a^{\prime}, h^{\prime}, e^{\prime}\right)$. This is not displayed in the value functions for employed and unemployed individuals and DI recipients for simplicity and to avoid the equations from becoming too long.
} 


$$
\begin{aligned}
V^{E}(j, a, g, h) & =\max _{c}\left\{u\left(c, 1-B_{j, h}^{e}\right)\right. \\
& +\beta \rho_{j} E\left[(1-\sigma) \max \left\{V^{E}\left(j^{\prime}, a^{\prime}, g^{\prime}, h^{\prime}\right), V^{U}\left(j^{\prime}, a^{\prime}, g^{\prime}, h^{\prime}, e^{\prime}, 1,0\right)\right\}\right. \\
& \left.\left.+\sigma V^{U}\left(j^{\prime}, a^{\prime}, g^{\prime}, h^{\prime}, e^{\prime}, 1,1\right)\right]\right\}
\end{aligned}
$$

subject to

$$
a^{\prime}=\left(1-\tau^{l}\right)\left(g \cdot w-p_{H I}\right)+\left[1+r\left(1-\tau^{k}\right)\right] k-\left(1-q_{H I}\right) m(j, h)+x
$$

Unemployed individuals: Unemployed individuals choose consumption, search effort and whether to apply for the DI or not. Note that only eligible individuals can apply for the DI and the indicator control $i_{D}=0$, otherwise.

$$
\begin{aligned}
& V^{U}\left(j, a, g, h, e, d_{U}, i_{U}\right)=\max _{c, s, i_{D}}\left\{u\left(c, 1-B_{j, h}^{s}(s)\right)+\beta \rho_{j} E[\right. \\
& \left(1-i_{D}\right) \pi^{s}(s) \max \left\{V^{E}\left(j^{\prime}, a^{\prime}, g^{\prime}, h^{\prime}\right), V^{U}\left(j^{\prime}, a^{\prime}, g^{\prime}, h^{\prime}, e, d_{U}+1, i_{U}^{\prime}\right)\right\} \\
& +\left(1-i_{D}\right)\left(1-\pi^{s}(s)\right) V^{U}\left(j^{\prime}, a^{\prime}, g^{\prime}, h^{\prime}, e, d_{U}+1, i_{U}^{\prime}\right) \\
& +i_{D}\left(1-\pi_{D}\right) V^{U}\left(j^{\prime}, a^{\prime}, g^{\prime}, h^{\prime}, e, d_{U}+1, i_{U}^{\prime}\right) \\
& \left.\left.+i_{D} \cdot \pi_{D} \cdot V^{D}\left(j^{\prime}, a^{\prime}, g^{\prime}, h^{\prime}, e, 0\right)\right]\right\}
\end{aligned}
$$

subject to

$$
a^{\prime}=\left[1+r\left(1-\tau^{k}\right)\right] k+i_{U I} \cdot b_{U}(e)-m(j, h)+x
$$

DI recipients: DI recipients choose consumption. If eligible to receive Medicare benefits, the indicator state $i_{M}=1$ and a fraction $q_{M}$ of gross expenditures are paid by Medicare.

$$
V^{D}\left(j, a, h, e, i_{M}\right)=\max _{c}\left\{u(c, 1)+\beta \rho_{j} E V^{D}\left(j^{\prime}, a^{\prime}, h^{\prime}, e, i_{M}^{\prime}\right)\right\}
$$

subject to

$$
a^{\prime}=\left[1+r\left(1+\tau^{k}\right)\right] k+b_{D}(e)-\left(1-i_{M} \cdot q_{M}\right) m(j, h)+x
$$

Retirees: Retired individuals receive social security and Medicare benefits and choose the level of consumption.

$$
V^{R}(j, a, h, e)=\max _{c}\left\{u(c, 1)+\beta \rho_{j} E V^{R}\left(j^{\prime}, a^{\prime}, h^{\prime}, e\right)\right\}
$$

subject to

$$
a^{\prime}=\left[1+r\left(1+\tau^{k}\right)\right] k+s s(e)-\left(1-q_{M}\right) m(j, h)+x
$$




\subsection{Competitive stationary equilibrium}

Individual states are $S_{E}=(j, a, g, h), S_{U}=\left(j, a, g, h, e, d_{U}, i_{U}\right)$ and $S_{D}=\left(j, a, h, e, i_{M}\right)$ for employed individuals, unemployed and disability recipients, respectively and $S_{R}=$ $(j, a, h, e)$ for retirees. Let the state space of four types of individuals be denoted as $\mathbb{S}^{E}, \mathbb{S}^{U}, \mathbb{S}^{D}$ and $\mathbb{S}^{R}$, and the entire state space of all individuals as $\mathbb{S}$ with $S \in \mathbb{S}$ being the general state vector of an individual including the employment and retirement state $N \in\{E, U, D, R\}$.

The equilibrium is given by allocation functions of individuals in each state; health insurance premium; accidental bequests; taxes on labor income, capital income and consumption; unemployment insurance, disability insurance, social insurance, social security and Medicare programs; a set of value functions $\left\{V^{E}\left(S_{E}\right)\right\}_{S_{E} \in \mathbb{S}^{E}},\left\{V^{U}\left(S_{U}\right)\right\}_{S_{U} \in \mathbb{S}^{U}}$, $\left\{V^{D}\left(S_{D}\right)\right\}_{S_{D} \in \mathbb{S}^{D}}$ and $\left\{V^{R}\left(S_{R}\right)\right\}_{S_{R} \in \mathbb{S}^{R}}$; and distribution of individuals over the state space given by $\mu(S)$, such that

1. The allocations solve the maximization problem of individuals in each state as described in section 2.4 .

2. Health insurance premium is determined as

$$
p_{H I}=\frac{\int q_{H I} \cdot m(j, h) \mu(S \mid N=E) d S}{\int \mu(S \mid N=E) d S}
$$

3. The accidental bequest transfer $x$ matches the assets of the deceased per surviving individual.

$$
x=\frac{\int \widetilde{x}(S)\left(1-\rho_{j}\right) \mu(S) d S}{\int \rho_{j} \mu(S) d S}
$$

$\widetilde{x}(S)$ denotes accidental bequests left by an individual in state $S$ and $\widetilde{x} \equiv a^{\prime}-x$, where $a^{\prime}$ is as defined in section 2.4 for each employment type.

4. The government budget is satisfied.

$$
\begin{aligned}
& \tau^{l} \int\left(g \cdot w-p_{H I}\right) \mu(S) d S+\tau^{k} \cdot r \cdot K+\tau^{c} \cdot C= \\
& G+\int\left[b_{U}+b_{D}+s s+T_{S I}\right] \mu(S) d S+\int q_{M} \cdot m(j, h) \mu\left(S_{R},\left.S_{D}\right|_{i_{M}=1}\right) d S
\end{aligned}
$$

where aggregate saving $K$ and aggregate consumption $C$ are defined as $K=\int k \mu(S) d S$ and $C=\int c \mu(S) d S$.

5. The distribution of individuals across the state space is stationary, that is, $\mu_{t+1}(S)=$ $\mu_{t}(S)$ for any $S \in \mathbb{S}$.

\section{Calibration}

This section discusses parametrization of the model. The model period is two months. The unit of the model is an individual. The wage rate $w$ is set for normalization so that the average annual earnings in the model is 1 . The interest rate $r$ is set at $4 \%$ annually. Tables 3 to 5 summarize the calibrated parameters. 


\subsection{Demographics}

The life-span is stochastic and individuals face mortality risk every period, based on the life-table of Bell and Miller (2005). We assume a stochastic transition across age groups. ${ }^{6}$ Individuals go through four age groups, $j=1,2,3$ and 4 , which correspond to the annual age groups of 20 to 34 years old, 35 to 49,50 to 64 , and 65 to 100 . Individuals at the working age, $j=1,2$ and 3 , move to the next age group with probability $1 /(15 \times 6)=0.0111$ such that they will remain in a given working age group for 15 years on average, conditionally on surviving. The size of new entrants to the model grows at a constant rate $n=0.011$, the average population growth rate since 1950 .

\subsection{Preference, endowment and labor market}

Utility from consumption $c$ and leisure $l$ takes the form

$$
u(c, l)=\frac{\left(c^{\eta} l^{1-\eta}\right)^{1-\gamma}}{1-\gamma}
$$

We set the risk aversion parameter $\gamma$ at 2.0. ${ }^{7} \eta$ is set at 0.5 , that is, individuals are assumed to put an equal weight on consumption and leisure. The subjective discount factor $\beta$ takes the value 0.99 on an annual basis so that individuals accumulate wealth over the life-cycle and hold wealth worth about four times as large as the economy-wide average earnings prior to retirement (at age 50-64), as in the Survey of Consumer Finance (SCF) data. ${ }^{8}$

Work and search effort incur disutility, which we assume will cost leisure time of employed and unemployed individuals. Figure 1 shows the employment rates of individuals from the Panel Study of Income Dynamics (PSID) in 2006, where samples are heads of households. ${ }^{9}$ Employment rates are high at around 90 to $95 \%$ before reaching age 50 and then fall rapidly thereafter. The average employment rate at age $20-49$ is $92 \%$ and it falls to $82 \%$ at 50-64. We set the participation disutility before and after age 50 to match these average participation rates. In addition, the participation of individuals in bad health status falls much more sharply as they age than those in good health. Although we use the PSID data and its household samples for the life-cycle employment rates, we look at the employment data in the MEPS to assess the effect of health on participation to be consistent with the definition of health status that we use for health-related parameters in the model, as we discuss in section 3.3. The employment rate of those in bad health declines sharply by about $20 \%$ from age 35-49 to age 50-64. We assume a multiplicative

\footnotetext{
${ }^{6}$ We follow the method developed by Yaari (1965) and Blanchard (1985) and extended by papers including Gertler (1999) and Cagetti and De Nardi (2009) in overlapping generations models.

${ }^{7}$ The parameters imply a coefficient of relative risk aversion at 1.5 and intertemporal elasticity of substitution at 0.667, which lie in the range of estimates in the literature. See Attanasio (1999) and Blundell and MaCurdy (1999) for surveys.

${ }^{8}$ In the Survey of Consumer Finance (SCF) 2004, the average amount of assets held by age 50-64 households was $\$ 306,000$. Assuming two-member households and given the average earnings of $\$ 39,000$ in 2004 from the Census, an individual's assets are about 4 times as large as the average earnings.

${ }^{9}$ We exclude full-time students and assume that an individual is employed if he or she works at least 10 hours per week. Heads can be male or female.
} 
adjustment factor of about 8 for the disutility parameter of individuals in bad health to match this decline in the participation rates between the two age groups. The calibrated disutility parameters $B_{j, h}^{e}$ are $\{0.042,0.042,0.070\}$ for age groups $j=1,2$ and 3 in $\operatorname{good}$ health, respectively, and the parameters are 8 times higher at $\{0.33,0.33,0.55\}$ for those in bad health.

An unemployed individual incurs disutility $B_{j, h}^{s}(s)=\bar{B}_{j, h}^{s} \frac{(1-s)^{\zeta}-1}{\zeta}$ by extending search effort $s \in[0,1]$. The parameter $\bar{B}_{j, h}^{s}$ is set at $-B_{j, h}^{e} \zeta$ so that it takes the same value as the participation cost when the maximum search effort is extended, i.e. $s=1.0$. The curvature parameter $\zeta$ is set at 0.98, making the search cost close to linear as in Alvarez and Veracierto (2001).

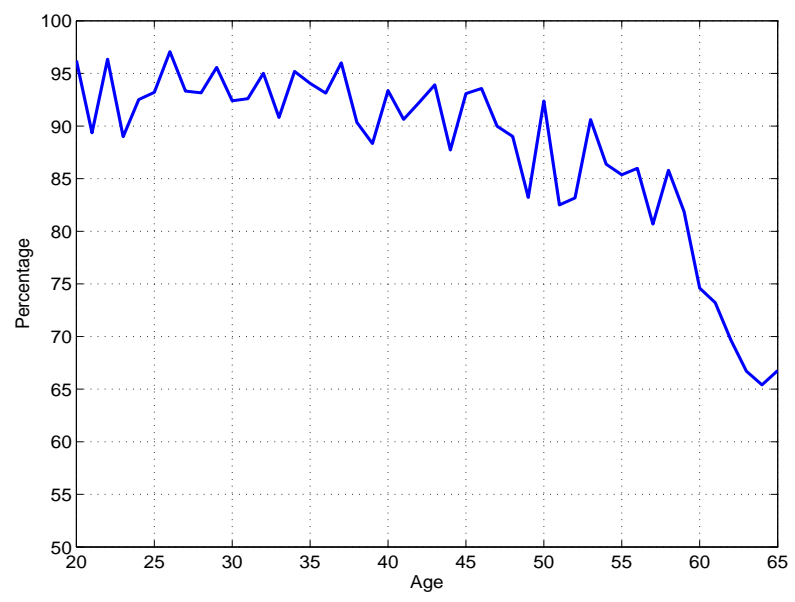

Figure 1: Employment rate over the life-cycle (Source: PSID)

The labor skill of an individual $g$ lies in $[g, \bar{g}]=[0.1,1.0]$ Individuals can accumulate skills while employed. We calibrate the transition matrix of skills $\Gamma_{j}^{E}\left(g, g^{\prime}\right)$ for employed individuals in each age group based on the earnings growth rate in the Census data in 2010. The skills of individuals are assumed to grow at the average annual rate of $9.5 \%$ at age $20-34,1.0 \%$ at age $35-49$ and $0.0 \%$ at age $50-64$, and the transition matrix $\Gamma_{j}^{E}\left(g, g^{\prime}\right)$ is computed to match these statistics.

Empirical estimates of skill depreciation rates while out of labor force come in a wide range. Keane and Wolpin (1997) estimate the annual human capital depreciation rate of $30.5 \%$ (white collar) and 9.6\% (blue collar) and Jacobson et al. (1993)'s estimates are lower, at around $10 \%$. We assume that skills of non-employed individuals fall at an annual rate of $15 \%$, the value used in Pavoni and Violante (2007) and discretize the process into a transition matrix $\Gamma_{j}^{N}\left(g, g^{\prime}\right)$.

The search technology is linear in the search effort, $\pi^{s}(s)=\xi \cdot s$, and the parameter $\xi$ is set at 0.5 , which implies that an unemployed individual finds a job in two periods, or four months, on average when the maximum search effort is extended. ${ }^{10}$

\footnotetext{
${ }^{10}$ As we discuss in section 4 , most unemployed individuals who choose non-zero search intensity $(s>0)$ extend the maximum search effort in the benchmark model. Therefore the calibrated parameter implies an average duration of about 4 months among those who search for a job.
} 
Table 1: Health status: annual transition matrices (Source: MEPS)

\begin{tabular}{|c|l|cc|}
\hline Age & & Good & Bad \\
\hline \multirow{2}{*}{$20-34$} & Good & 0.931 & 0.069 \\
& Bad & 0.469 & 0.531 \\
\hline \multirow{2}{*}{$35-49$} & Good & 0.898 & 0.102 \\
& Bad & 0.396 & 0.704 \\
\hline \multirow{2}{*}{$50-64$} & Good & 0.879 & 0.121 \\
& Bad & 0.259 & 0.741 \\
\hline \multirow{2}{*}{ above 65 5 Good } & 0.833 & 0.167 \\
& Bad & 0.199 & 0.801 \\
\hline
\end{tabular}

We set the exogenous job separation rate $\sigma$ at $2.7 \%$, which is the average rate of layoffs and discharges in recent years according to the Jobs Opening and Labor Turnover Survey (JOLTS) by the Bureau of Labor Statistics (BLS). ${ }^{11}$

\subsection{Health, medical expenditures and health insurance}

We use the Medical Expenditure Panel Survey (MEPS) to calibrate parameters related to health status, medical expenditures, health insurance and Medicare.

The MEPS is an annual survey of a representative sample of the civilian population with detailed information on demographics, health status, medical expenditures, and health insurance arrangement. We use the most recent panel of individual data (20082009) for the calibration.

The measure of health status in the MEPS is self-reported, ranked from 1 (excellent) to 5 (poor). Every annual MEPS survey has three waves and the health measure is present in each wave. We choose to define two levels of individuals' health status, good $h_{g}$ and bad $h_{b}$, based on the responses and define health as bad if the response is 4 or 5 in at least one of the waves in a particular year. The transition matrices of health status are reported in Table 1.

For medical expenditures $m(j, h)$, we use total gross expenditures reported by individual samples in the MEPS. ${ }^{12}$ For each age group and health status, we compute three expenditure levels with unequal probabilities (top 5 percent, 35 percent, and 60 percent), in order to capture the long tail in the distribution of the medical expenditures and a small probability of incurring very large and catastrophic expenditures. The distribution of medical expenditures by age and health status is displayed in Table 2.

\footnotetext{
${ }^{11}$ The layoff and discharge rate was $2.6-2.8 \%$ in $2005-2007$ before rising during the financial crisis and it declined to the average of $2.7 \%$ in 2010-2011.

${ }^{12} \mathrm{We}$ use the variable TOTEXP in the MEPS that represents total expenditures of an individual. The MEPS makes efforts to impute true expenditures that are actually paid, for example, by replacing missing data and accounting for systematic inconsistency between self-reported insurance payment and actual amount due to over-billing and subsequent discounting. To the best of our knowledge, the MEPS is the best data source available for the calibration of gross, rather than out-of-pocket, expenditures over the entire life-cycle for the general population.
} 
Table 2: Medical expenditures by age group and health status (in 2009 dollars) (Source: MEPS)

\begin{tabular}{|c|l|rrr|}
\hline \multirow{2}{*}{ Age } & Health & $60 \%$ & $35 \%$ & $5 \%$ \\
\hline \multirow{2}{*}{$20-34$} & Good & 133 & 2,375 & 15,856 \\
& Bad & 513 & 7,242 & 46,610 \\
\hline \multirow{2}{*}{$35-49$} & Good & 279 & 3,262 & 19,275 \\
& Bad & 993 & 11,584 & 66,236 \\
\hline \multirow{2}{*}{$50-64$} & Good & 738 & 5,635 & 33,778 \\
& Bad & 1,980 & 16,921 & 75,163 \\
\hline \multirow{2}{*}{ above 65 } & Good & 1,730 & 9,038 & 38,525 \\
& Bad & 4,042 & 23,363 & 82,593 \\
\hline
\end{tabular}

Based on the average expenditures covered by private health insurance and Medicare, we use the expenditure coverage ratio of $q_{H I}$ at 0.75 and $q_{M}$ at 0.60 , respectively. The premium of the private health insurance $p_{H I}$ paid by each employed individual is set at $\$ 2,700$ in 2009 dollars so that the insurance provider will break even, that is, revenues from insurance premium equal total spending that covers a fraction $q_{H I}$ of gross expenditures incurred by all insured individuals. The insurance premium is subtracted from the pre-tax wage bill.

\subsection{Government}

When individuals lose a job exogenously through a layoff, they become entitled to unemployment insurance benefits for the maximum duration of 6 months. The benefit replaces $\kappa^{U}=50 \%$ of earnings prior to the job separation. Benefits are capped above at $\$ 400$ per week, which is the average upper bound of benefits across states in the U.S.

We assume mandatory retirement at age 65 , or once reaching age group $j=4$. Individuals receive social security benefits and gain access to Medicare coverage thereafter. Social security benefits are determined as a function of previous earnings according to the formula (15) below. Benefits, the Primary Insurance Amount (PIA), are computed using a piecewise linear function of $e$ with three bend points, $\$ 8,928, \$ 53,796$ and $\$ 106,800$ in 2009 dollars. The benefit (PIA) is capped above with the maximum base for the past earnings $e$ of $\$ 106,800$.

$$
P I A= \begin{cases}0.9 \times e & \text { if } e<\$ 8,928 \\ \$ 8,035+0.32 \times(e-\$ 8,928) & \text { if } \$ 8,929 \leq e<\$ 53,796 \\ \$ 22,393+0.15 \times(e-\$ 53,796) & \text { if } e \geq \$ 53,796\end{cases}
$$

The DI benefits are set according to the same formula as the social security benefits. Once individuals are unemployed for more than two model periods (4 months), they can apply for the DI benefits when they face a disability shock, which occurs with probability $\theta_{j, h}$. According to the Annual Report of the SSA (2007), the percentage of the population 
covered by the DI was $0.97 \%, 2.92 \%$ and $8.92 \%$ for age groups of $20-34,35-49$ and $50-64$, respectively. We calibrate the parameter $\theta_{j, h}$ to target these average statistics. More precisely, we assume that only individuals in bad health receive the disability shock, that is, $\theta_{j, h}=0$ if $h=h_{g}$. We calibrate the probability of disability shock among the badhealth individuals to match the percentage of covered individuals. $\theta_{j, h_{b}}$ is set at $8.5 \%$ for age $20-49$ and $5.1 \%$ for $50-64 .^{13}$

In the data, about $1 \%$ of individuals at the youngest age group receive the DI benefits. It is, however, difficult to generate such young individuals opting for the permanent disability coverage given the features of the model. Therefore we add an assumption that some individuals in bad health are disabled and covered by the DI as they enter the model and set the probability of such incidence so that $1 \%$ of individuals are covered by the DI among those in the youngest age group of our model.

Autor and Duggan (2010) report that out of the 1.766 million applications for DI benefits 902,000 , or $51.1 \%$, were awarded benefits in 2005 . The figure includes awards rewarded not only in the initial stage of process but also in subsequent stages of reconsideration and appeals. We set the probability $\pi_{D}$ that the applications are accepted and individuals are granted the DI benefits at 50\%. We assume that if the application is unsuccessful and benefits are not awarded, unemployed individual can reapply but have to wait for at least four months (2 model periods) before initiating the new application. The assumption is based on the fact that the average wait time for the initial decision is 4.3 months.

We assume that the DI benefits will continue for the rest of the working-age life and they are terminated upon death or retirement, whichever comes first. In reality there is a probability that the DI benefits are terminated exogenously as a result of the Continuing Disability Review (CDR). The probability, however, of the termination is extremely small. Also there are very few individuals who return to work and engage in the Substantial Gainful Activity (SGA) that triggers the termination of the benefits. According to the Annual Report or the SSA (2007), the probability of termination for the reasons related to medical standards and employment was only $0.74 \%$, which implies that the termination event will occur every 135 years on average.

Once an individual has received the DI for two years, he or she will automatically have access to Medicare coverage. In the model, DI recipients without Medicare coverage will face probability $\pi_{M}$ of becoming eligible for Medicare and we set the value so that they will gain the access in two years on average.

The asset threshold level $\underline{a}$ for the social insurance transfer is set to guarantee the minimum consumption level of $\$ 4,000$ on annual basis. The level is close to the values estimated in De Nardi et al. (2010) at $\$ 2,700$ (in 1998, equivalent to $\$ 3,600$ in 2009 dollars) and Palumbo (1999) at $\$ 2,000$ (in 1985, $\$ 4,000$ in 2009 dollars). In the model, the social insurance stands in for means-tested transfer programs, such as Medicaid, that would absorb the unpayable debt from the medical expenditure shocks. Since we do not explicitly model more active welfare programs, such as the Temporary Assistance for Needy Families (TANF) or Food Stamps, we use a lower value than in other papers, such as Hubbard et al. (1995), who use a much higher value of $\$ 7,000$ (in 1984, $\$ 14,500$ in

\footnotetext{
${ }^{13}$ Unconditionally of health status, $1.5 \%$ of individuals at age $20-49$ and $1.6 \%$ of those at age $50-64$ will receive the disability shock.
} 
2009 dollars).

Medicare covers $q_{M}=60 \%$ of gross expenditures for eligible individuals, based on the average expenditure coverage rate among Medicare recipients in MEPS 2009.

Tax rates on consumption, labor income, and capital income are set at 5\%,25\% and $30 \%$, respectively, close to the estimates of effective tax rates in Mendoza et al. (1994).

Residuals from the government budget are assumed to be the expenditures of the government that are not associated with the programs that we explicitly model as discussed above. Note that the level of these expenditures are fixed when we run the counterfactual experiments so that changes in fiscal cost driven by an alternative policy and allocational distortions can be quantified.

Table 3: Parameters of the model (1)

\begin{tabular}{|c|c|c|}
\hline Parameter & Description & Values/source \\
\hline \multicolumn{3}{|c|}{ Demographics } \\
\hline \multirow{3}{*}{$\begin{array}{l}n \\
\left\{\rho_{j}\right\}_{j=1}^{J} \\
\left\{\phi_{j}\right\}_{j=1}^{J-1}\end{array}$} & Population growth rate & $1.1 \%$ \\
\hline & Conditional survival probabilities & Bell and Miller (2005) \\
\hline & Age-transition probabilities & see text \\
\hline \multicolumn{3}{|l|}{ Preference } \\
\hline \multirow{4}{*}{$\begin{array}{l}\beta \\
u(c, l)\end{array}$} & Subjective discount factor (annual) & 0.99 \\
\hline & Consumption-leisure utility & \\
\hline & Risk aversion $\gamma$ & 2.0 \\
\hline & Consumption weight $\eta$ & 0.5 \\
\hline \multirow[t]{3}{*}{$B_{j, h}^{e}$} & Disutility from participation & \\
\hline & Good health & $\{0.042,0.042,0.07\}$ \\
\hline & Bad health & $\{0.33,0.33,0.55\}$ \\
\hline \multirow[t]{3}{*}{$B_{j, h}^{s}(s)$} & Search disutility & \\
\hline & Scale parameter $\bar{B}_{j, h}^{s}$ & $-\bar{B}_{j, h}^{e} \zeta$ \\
\hline & Curvature parameter $\zeta$ & 0.98 \\
\hline \multicolumn{3}{|c|}{ Labor market frictions } \\
\hline \multirow[t]{2}{*}{$\pi^{s}(s)$} & Search technology (job finding rate) & \\
\hline & Linear coefficient $\xi$ & 0.5 \\
\hline$\sigma$ & Prob. of exogenous separation & $2.7 \%$ \\
\hline \multicolumn{3}{|c|}{ Skill process } \\
\hline \multirow[t]{2}{*}{$\Gamma_{j}^{E}\left(g, g^{\prime}\right)$} & Skill transition, employed & \\
\hline & Skill growth rate (annual) & $\{9.5 \%, 1.0 \%, 0.0 \%\}$ \\
\hline \multirow[t]{2}{*}{$\Gamma_{j}^{N}\left(g, g^{\prime}\right)$} & Skill transition, non-working & \\
\hline & Skill depreciation rate (annual) & $15 \%$ \\
\hline
\end{tabular}


Table 4: Parameters of the model (2): health, expenditures and health insurance

\begin{tabular}{|lll|}
\hline Parameter & Description & Values/source \\
\hline$\pi_{j}^{h}\left(h, h^{\prime}\right)$ & Health transition & MEPS \\
$m(j, h)$ & Medical expenditures & MEPS \\
\hline Health insurance & \\
$p_{H I}$ & Health insurance premium & Set in equilibrium \\
$q_{H I}$ & Expenditure coverage rate & $75 \%$, MEPS \\
\hline
\end{tabular}

Table 5: Parameters of the model (3): government

\begin{tabular}{|c|c|c|}
\hline Parameter & Description & Values/source \\
\hline \multicolumn{3}{|l|}{ Taxes } \\
\hline$\tau^{l}$ & Labor income tax rate & $25 \%$ \\
\hline$\tau^{c}$ & Consumption tax rate & $5 \%$ \\
\hline$\tau^{k}$ & Capital income tax rate & $30 \%$ \\
\hline \multicolumn{3}{|c|}{ Social security } \\
\hline$s s(e)$ & Benefit formula & SSA (see text) \\
\hline$j_{R}$ & Retirement age & 65 years old \\
\hline \multicolumn{3}{|l|}{ Medicare } \\
\hline$q_{M}$ & Expenditure coverage rate & $60 \%$, MEPS \\
\hline \multicolumn{3}{|c|}{ Unemployment insurance } \\
\hline$\kappa_{U}$ & Replacement rate & $50 \%$ \\
\hline$\overline{b_{U}}$ & Benefit upper limit & $\$ 400$ per week \\
\hline$\overline{d_{U}}$ & Maximum duration & 6 months \\
\hline \multicolumn{3}{|c|}{ Disability insurance } \\
\hline$b_{D}(e)$ & Benefit formula & SSA (see text) \\
\hline$\pi_{D}$ & Application acceptance rate & $50 \%$ \\
\hline$\theta_{j, h}$ & Disability shock & See text \\
\hline$\pi_{M}$ & Medicare eligibility shock & $8.33 \%$ (in 2yrs avg) \\
\hline \multicolumn{3}{|c|}{ Social insurance } \\
\hline$\underline{a}$ & Consumption floor & $\$ 4,000$ (annual) \\
\hline
\end{tabular}

\section{Numerical results}

This section presents the benchmark model and discusses the results of experiments.

\subsection{Benchmark model}

In this section we will discuss the performance of the benchmark model in the key dimensions of an individual's life-cycle, focusing on the profiles of employment status and DI coverage.

Individuals enter the model economy with no asset and they quickly start to accumulate savings for precautionary and retirement reasons. The average assets are about 1.3 
times as large as the average annual earnings at age 20-34, or $\$ 56,000$ in 2009 dollars. The assets grow to reach $\$ 134,000$ at age $35-49$ and $\$ 175,000$ ( $\$ 350,000$ per two-member household) at age 50-64 or 4.0 times the average earnings. Table 6 compares the life-cycle profile of wealth to the data from the Survey of Consumer Finance (SCF). ${ }^{14}$ As shown in Table 7, the consumption profile also exhibits a hump shape along the life-cycle, although the growth prior to retirement is much more moderate than asset and the profile is flatter.

Table 6: Assets by age (individuals, in 2009 dollars)

\begin{tabular}{|l|c|c|}
\hline Age & Model & Data $(\mathrm{SCF})$ \\
\hline $20-34$ & 56,000 & 31,000 \\
$35-49$ & 134,000 & 101,000 \\
$50-64$ & 175,000 & 174,000 \\
$65-100$ & 92,000 & 134,000 \\
\hline all ages & 109,000 & 112,000 \\
\hline
\end{tabular}

Table 7: Consumption by age (individuals, in 2009 dollars)

\begin{tabular}{|l|c|}
\hline Age & Consumption \\
\hline $20-34$ & 47,400 \\
$35-49$ & 51,300 \\
$50-64$ & 56,400 \\
$65-100$ & 40,900 \\
\hline all ages & 49,000 \\
\hline
\end{tabular}

Table 8 shows the distribution of employment status by age group, compared to the data that is shown in the top section. The data are based on the PSID for employment rates and the SSA for the DI coverage, both in 2007. The unemployed is defined as those who are not employed or receiving the DI benefits. The employment rate is above $90 \%$ before age 50, but it falls quickly thereafter as more individuals start to leave the labor market. Both the number of unemployed individuals and DI recipients rise as individuals age. About $20 \%$ of the unemployed in our model are not searching at all (i.e. $s=0.0$ ) and the percentage of individuals who are searching (i.e. $s>0.0$ ) is about $5.0 \%$ out of the working-age population in the model.

\footnotetext{
${ }^{14}$ The data is based on the SCF in 2004 and the figures are adjusted for 2009 dollars using the CPI.
} 
Table 8: Employment status distribution by age

\begin{tabular}{|l|c|c|c|}
\hline Age & Employed & Unemployed & Disability \\
\hline Data (PSID and SSA, 2007) \\
\hline $20-34$ & $93.5 \%$ & $5.5 \%$ & $1.0 \%$ \\
$35-49$ & $91.2 \%$ & $5.9 \%$ & $2.9 \%$ \\
$50-64$ & $81.6 \%$ & $9.5 \%$ & $8.9 \%$ \\
\hline \hline Model \\
\hline $20-34$ & $94.1 \%$ & $5.0 \%$ & $1.0 \%$ \\
$35-49$ & $91.4 \%$ & $5.7 \%$ & $2.9 \%$ \\
$50-64$ & $82.2 \%$ & $8.8 \%$ & $9.0 \%$ \\
\hline all ages & $90.1 \%$ & $6.2 \%$ & $3.7 \%$ \\
\hline Model: good health \\
\hline 20-34 & $94.2 \%$ & $5.0 \%$ & $0.9 \%$ \\
$35-49$ & $92.3 \%$ & $5.1 \%$ & $2.6 \%$ \\
$50-64$ & $88.2 \%$ & $5.2 \%$ & $7.9 \%$ \\
\hline all ages & $91.9 \%$ & $5.1 \%$ & $3.1 \%$ \\
\hline Model: bad health & \\
\hline $20-34$ & $93.4 \%$ & $4.9 \%$ & $1.7 \%$ \\
$35-49$ & $88.6 \%$ & $5.4 \%$ & $3.8 \%$ \\
$50-64$ & $71.7 \%$ & $17.1 \%$ & $11.3 \%$ \\
\hline all ages & $83.3 \%$ & $10.5 \%$ & $6.2 \%$ \\
\hline
\end{tabular}

Recall from section 3 that we calibrated the model to target employment rates and the percentage of individuals covered by the DI. As discussed in section 3, disutility of participation for individuals in good health rises from 0.042 before reaching age 50 to 0.07 thereafter, an increase of two-thirds in disutility, which also applies to those in bad health. The rise accounts for negative factors that could rise in age and add to the disutility of working, which the model does not capture (such as additional cost of dressing up and taking public transportation to work early in the morning or the opportunity cost of staying away from children and grant-children at home, etc).

Participation disutility is significantly higher for individuals in bad health, about eight times as high as those in good health. The additional disutility helps explain lower participation rates among the unhealthy individuals and in particular, the sizeable decline in participation that occurs after age 50 .

Since the search effort of unemployed individuals incurs disutility that rise in age and deterioration of health status, search incentives are significantly lower among those in bad health and at higher ages, as shown in Table 9. Many of the individuals who extend positive search effort choose the maximum search intensity. Possibility of receiving the DI benefits once eligibility conditions are met also discourages search efforts. 
Table 9: Average search effort of the unemployed

\begin{tabular}{|l|c|c|c|}
\hline Age & All & Good health & Bad health \\
\hline $20-34$ & 1.000 & 1.000 & 1.000 \\
$35-49$ & 0.877 & 1.000 & 0.612 \\
$50-64$ & 0.539 & 0.998 & 0.218 \\
\hline
\end{tabular}

\subsection{Policy experiments}

In this section we simulate a model under two sets of counterfactual assumptions about policies and parameterizations. In the first, we run a model with alternative features of the DI system in order to understand the incentives to apply for the DI and the distribution of employment status driven by the details of the system. In the second, we consider alternative scenarios about the labor market frictions and quantify the impact on labor supply and the roles of the DI.

We assumed in the benchmark model that the residuals from the government budget constraint are government expenditures, $G$, which are "thrown into the ocean" and do not play a role in the model. In order to account for changes in the fiscal cost associated with alternative DI systems or labor market frictions, we assume that the same amount of government expenditures as in the benchmark have to be financed by taxes and we adjust the tax rate on labor income $\tau^{l}$ in each experiment.

\subsubsection{Disability insurance system: Medicare and cash benefits}

One of the features that we introduced in our model was the in-kind Medicare benefit that DI recipients automatically are entitled to once they have received the DI benefits for 2 years. To quantify the effect of the Medicare benefit on the incentives to apply for the DI, we simulate a model without Medicare benefits for DI recipients. Medicare benefits continue to be paid for retirees.

As shown in the second section of Table 10, fewer individuals would apply for the DI if Medicare benefits were eliminated. The percentage of DI recipients declines from $2.9 \%$ to $1.1 \%$ among age $35-49$ individuals and from $9.0 \%$ to $6.7 \%$ at age $50-64$. Unemployed individuals extend more search effort to return to employment, as shown in Table 11. The majority of individuals choose the maximum search effort at age 20-49, whether they are healthy or unhealthy. Although unhealthy individuals incur greater disutility from work, they would still want to search hard and return to the labor force. They would, otherwise, have to pay for medical expenditures on their own, not only when they are young and expenditures are relatively low, but all the way until retirement when Medicare benefits are granted for retirees. Staying out of the labor force for a long time could result in their assets falling so low that they have to rely on social insurance.

The above experiment shows the importance of Medicare benefits that the DI recipients will eventually have access to. The benefits, however, are not available immediately and there is a waiting period of 2 years before Medicare starts to cover the DI recipients. The third section of Table 10 shows the employment outcome when we assume that 
Medicare is available for all DI recipients without a waiting period. Compared to the benchmark model, there are more individuals covered by the DI, but the effect is relatively small quantitatively. The percentage of DI recipients increases from $3.7 \%$ of working-age population to $4.0 \%$, which is a much smaller change than when Medicare benefits are eliminated. It is the existence of the DI benefit which individuals will receive eventually that they appear to find beneficial and the waiting period of the length as it is now does not seem to affect incentives to apply in a significant way.

The DI coverage is also sensitive to the level of the cash benefits. In the last section of Table 10, DI benefits are reduced by $20 \%$, by scaling down the benefit schedule proportionally. The total number of unemployed and DI recipients will decline by 0.3 and 1.4 percentage points of the working-age population, respectively, and the overall employment rate would rise by 1.7 percentage points. The benefit cut is most effective in encouraging participation of older individuals and the employment rate at age 50-64 rises by 3.5 percentage points, from $82.2 \%$ to $85.7 \%$.

Table 10: Employment status with alternative DI systems

\begin{tabular}{|l|c|c|c|}
\hline Age & Employed & Unemployed & Disability \\
\hline Benchmark model \\
\hline $20-34$ & $94.1 \%$ & $5.0 \%$ & $1.0 \%$ \\
$35-49$ & $91.4 \%$ & $5.7 \%$ & $2.9 \%$ \\
$50-64$ & $82.2 \%$ & $8.8 \%$ & $9.0 \%$ \\
\hline all ages & $90.1 \%$ & $6.2 \%$ & $3.7 \%$ \\
\hline \hline No Medicare for DI recipients \\
\hline $20-34$ & $94.1 \%$ & $5.0 \%$ & $1.0 \%$ \\
$35-49$ & $93.8 \%$ & $5.1 \%$ & $1.1 \%$ \\
$50-64$ & $84.6 \%$ & $8.7 \%$ & $6.7 \%$ \\
\hline all ages & $91.5 \%$ & $6.0 \%$ & $2.5 \%$ \\
\hline \hline Medicare w/o 2-year waiting period \\
\hline $20-34$ & $94.1 \%$ & $5.0 \%$ & $1.0 \%$ \\
$35-49$ & $90.9 \%$ & $5.8 \%$ & $3.3 \%$ \\
$50-64$ & $81.6 \%$ & $8.9 \%$ & $9.5 \%$ \\
\hline all ages & $89.7 \%$ & $6.3 \%$ & $4.0 \%$ \\
\hline \hline DI benefit cut by 20\% & $5.0 \%$ & $1.0 \%$ \\
\hline $20-34$ & $94.1 \%$ & $5.1 \%$ & $1.0 \%$ \\
\hline $35-49$ & $93.9 \%$ & $8.3 \%$ & $6.0 \%$ \\
\hline $50-64$ & $85.7 \%$ & $5.9 \%$ & $2.3 \%$ \\
\hline all ages & $91.8 \%$ & & \\
\hline \multicolumn{4}{|l|}{$5 \%$} \\
\hline
\end{tabular}


Table 11: Search effort and tax rate with alternative DI systems

\begin{tabular}{|l|c|c|c|c|}
\hline & Benchmark & $\begin{array}{c}\text { No Medicare } \\
\text { for DI recipients }\end{array}$ & $\begin{array}{c}\text { Medicare w/o } \\
\text { waiting period }\end{array}$ & $\begin{array}{c}\text { DI benefit cut } \\
\text { by 20\% }\end{array}$ \\
\hline \multicolumn{4}{|l|}{ Average search effort } \\
\hline Age 20-34 & 1.000 & 1.000 & 1.000 & 1.000 \\
Age 35-49 & 0.877 & 0.998 & 0.860 & 0.999 \\
Age 50-64 & 0.539 & 0.556 & 0.531 & 0.582 \\
\hline Labor income tax rate \\
\hline$\tau^{l}(\%)$ & $25.0 \%$ & $24.3 \%$ & $25.2 \%$ & $24.0 \%$ \\
\hline
\end{tabular}

The bottom row in Table 11 shows labor income tax rates that balance the government budget in each experiment. Without Medicare benefits for DI recipients, the government is able to reduce expenditures in the amount corresponding to 0.7 percentage points of labor income. If Medicare benefits are offered without a two-year waiting period, there will be additional expenditures but the fiscal cost is not so large, requiring an increase of 0.2 percentage points in labor income taxes. Reducing the cash benefits by one-fifth would enable the government to reduce the labor income tax by one percentage point, giving individuals additional incentives to work.

A rise in medical expenditures: As shown above, Medicare benefit is an important part of the disability insurance and gives major incentives to apply for the DI benefits among many working-age individuals. As is well known, the growth of the medical expenditures has been above that of the overall economy in the past decades and the share of medical expenses in the GDP rose sharply from less than 10\% in early 1980s to $17.9 \%$ in 2009. ${ }^{15}$ To assess the impact of a potential further rise in medical expenditures, we simulate the model assuming that medical expenditures are $20 \%$ above the level in the benchmark model. As shown in Table 12, such a change will lead to a one percentage point increase in the DI coverage, from $3.7 \%$ to $4.7 \%$ and the employment rate falls by 1.2 percentage points. Government spending for additional disability benefits and Medicare coverage not only for eligible DI recipients but also retirees rises in response to the increase in medical expenditures. The labor income tax rate has to increase by 1.7 percentage points to $26.7 \%$ to balance the government budget. The decline in the after-tax wage will generate further disincentives to work.

\footnotetext{
${ }^{15}$ The figures are from the Centers of Medicare and Medicaid Services (CMS.gov).
} 
Table 12: Employment status with 20\% higher medical expenditures

\begin{tabular}{|l|c|c|c|}
\hline Age & Employed & Unemployed & Disability \\
\hline Benchmark model \\
\hline $20-34$ & $94.1 \%$ & $5.0 \%$ & $1.0 \%$ \\
$35-49$ & $91.4 \%$ & $5.7 \%$ & $2.9 \%$ \\
$50-64$ & $82.2 \%$ & $8.8 \%$ & $9.0 \%$ \\
\hline all ages & $90.1 \%$ & $6.2 \%$ & $3.7 \%$ \\
\hline \hline \multicolumn{4}{|l|}{ Higher medical expenditures } \\
\hline $20-34$ & $94.1 \%$ & $5.0 \%$ & $1.0 \%$ \\
$35-49$ & $89.9 \%$ & $6.1 \%$ & $4.1 \%$ \\
$50-64$ & $79.6 \%$ & $9.3 \%$ & $11.1 \%$ \\
\hline all ages & $88.9 \%$ & $6.5 \%$ & $4.7 \%$ \\
\hline
\end{tabular}

\subsubsection{Labor market frictions: a rise in the exogenous separation rate and a decline in the job finding rate}

We consider economies that face a different level of labor market frictions. First, we simulate a model where the exogenous separation rate $\sigma$ is $20 \%$ higher. Second, we assume a lower likelihood of finding a job, by reducing the linear coefficient parameter $\xi$ of the search technology by $20 \%$.

Although these experiments are partly motivated by what we typically observe during an economic downturn, when unemployment rises due to a combination of a rise in job separations and a fall in hiring, the analysis here is based on the comparison of stationary economies and effects in the long-run, rather than short-run effects at business-cycle frequencies. The effects presented below could be considered as an upper bound of what we might observe in the short-run. ${ }^{16}$

Table 13 shows the distribution of the employment status under alternative separation and job finding rates. More frictions in the labor market raise both unemployment and DI coverage. A $20 \%$ increase in the likelihood of exogenous separations will lower the employment rate by 1.7 percentage points, from $90.1 \%$ to $88.4 \%$. Lower job finding rates have similar effects and the employment rate falls by 2.1 percentage points to $88.0 \%$. In order to better understand the roles of the DI when there is a change in labor market frictions, we simulate a model that is exactly the same as the benchmark economy except that there is no DI in entirety. Working-age individuals are either employed or unemployed and the unemployed individuals search and transition back to employment or remain

\footnotetext{
${ }^{16}$ The magnitude of the change in job separation and job finding rates we simulate here is similar to what was observed during the recent recession in late 2000s, when the unemployment rose from less than $5 \%$ in 2006-2007 to the peak of $10 \%$ in late 2009. According to the Job Openings and Labor Turnover Survey (JOLTS) of the Bureau of Labor Statistics (BLS), the monthly average rate of layoffs and discharges increased from $1.3 \%$ in $2006-2007$ to $1.5-1.7 \%$ in 2008-2009, which declined thereafter to reach $1.3 \%$ in 2011 . The hires rate, defined as the number of hires during the entire month as a percentage of total employment, declined from $3.2 \%$ in 2006-2007 to $2.6 \%$ in 2008 and $1.8 \%$ in 2009 . Contrary to the recovery in the frequency of layoffs and discharges, the hires rate has remained higher than the pre-recession level, and stayed at 2.4-2.6\% in 2011 and the first half of 2012.
} 
unemployed. As shown in Table 13, the average employment rate is $94.0 \%$, about 4 percentage points higher than in the benchmark model and the unemployment rate is $6.0 \%$, similar to the level in the benchmark. When the job separation rate rises by $20 \%$ in this economy, the employment rate falls by 1.1 percentage points, from $94.0 \%$ to $92.9 \%$. The decline is significantly smaller than in a model with the DI, where the employment rate fell by 1.7 percentage points. Similarly, if the job finding rate falls by $20 \%$, the employment rate declines by 1.3 percentage points to $92.7 \%$, a smaller decline than a fall of 2.1 percentage points in our benchmark model with the DI.

The simulations suggest that a model without the DI could significantly underestimate employment effects due to a change in labor market conditions. A higher separation rate will increase the size of unemployment and more individuals will be eligible to apply for the DI and settle in the absorbing state rises. A lower job finding rate will increase the duration of unemployment and generate similar changes. In addition, a longer spell of unemployment implies a greater depreciation of skills and DI cash benefits become relatively more attractive as they are tied to the earnings prior to the job separation.

Table 13: Employment status with alternative labor market frictions

\begin{tabular}{|l|c|c|c|}
\hline Age & Employed & Unemployed & Disability \\
\hline Benchmark model \\
\hline $20-34$ & $94.1 \%$ & $5.0 \%$ & $1.0 \%$ \\
$35-49$ & $91.4 \%$ & $5.7 \%$ & $2.9 \%$ \\
$50-64$ & $82.2 \%$ & $8.8 \%$ & $9.0 \%$ \\
\hline all ages & $90.1 \%$ & $6.2 \%$ & $3.7 \%$ \\
\hline \hline Higher separation rate \\
\hline $20-34$ & $93.1 \%$ & $5.9 \%$ & $1.0 \%$ \\
$35-49$ & $89.4 \%$ & $6.8 \%$ & $3.7 \%$ \\
$50-64$ & $79.8 \%$ & $9.9 \%$ & $10.3 \%$ \\
\hline all ages & $88.4 \%$ & $7.3 \%$ & $4.4 \%$ \\
\hline \hline Lower job finding rate \\
\hline $20-34$ & $92.9 \%$ & $6.1 \%$ & $1.0 \%$ \\
$35-49$ & $88.9 \%$ & $7.1 \%$ & $4.0 \%$ \\
$50-64$ & $79.1 \%$ & $10.2 \%$ & $10.8 \%$ \\
\hline all ages & $88.0 \%$ & $7.5 \%$ & $4.6 \%$ \\
\hline
\end{tabular}


Table 14: Employment status with alternative labor market frictions: model without disability insurance

\begin{tabular}{|l|c|c|}
\hline Age & Employed & Unemployed \\
\hline \multicolumn{3}{|l|}{ Model without DI } \\
\hline $20-34$ & $95.0 \%$ & $5.0 \%$ \\
$35-49$ & $94.9 \%$ & $5.1 \%$ \\
$50-64$ & $91.4 \%$ & $8.6 \%$ \\
\hline all ages & $94.0 \%$ & $6.0 \%$ \\
\hline \hline Higher separation rate \\
\hline $20-34$ & $94.1 \%$ & $5.9 \%$ \\
$35-49$ & $93.9 \%$ & $6.1 \%$ \\
$50-64$ & $89.8 \%$ & $10.2 \%$ \\
\hline all ages & $92.9 \%$ & $7.1 \%$ \\
\hline \hline Lower job finding rate \\
\hline $20-34$ & $93.9 \%$ & $6.1 \%$ \\
$35-49$ & $93.7 \%$ & $6.3 \%$ \\
$50-64$ & $89.7 \%$ & $10.3 \%$ \\
\hline all ages & $92.7 \%$ & $7.3 \%$ \\
\hline
\end{tabular}

\section{Conclusion}

This paper builds a life-cycle model of individuals who face various sources of uncertainty including employment, health status and medical expenditures. Individuals accumulate wealth for precautionary and retirement reasons, while the government provides partial insurance against the shocks through redistributive programs. Eligible individuals can apply for the disability insurance (DI), which provides both cash and Medicare benefits, and the latter is available after a waiting period of two years. The model is calibrated to approximate the pattern of employment status over the life-cycle.

This is the first paper with a structural life-cycle model that incorporates uncertainty in health and medical expenditures and endogenous enrollment in the DI system, which consists of both cash and in-kind medical benefits. The model allows us to quantify the role of each element of the DI system in the employment decisions of individuals over the life-cycle. We have shown that not only the cash benefits but also Medicare benefits are important to account for the level of the DI coverage among both young and oldage individuals. The DI coverage could drop significantly if its Medicare benefits were eliminated.

We also use the model to study the effect of labor market frictions. In simulating a rise in the job separation rate and a decline in the job finding rate by $20 \%$ respectively, we find that a model without the DI which otherwise is identical can underestimate the decline in employment rates by 0.6 to 0.9 percentage points, or by more than one-third.

One of the interesting extensions of the paper would be to incorporate the demographic transition and reforms of old-age entitlement programs; social security and Medicare for 
retirees. The coming shift in demographics and a rapid increase in the old-age dependency ratio imply an urgent need to reform existing pension and Medicare systems. The DI coverage, which rises in old ages before retirement can have a significant impact from a reform or even the demographic transition itself. This topic is left for future research.

\section{References}

Aiyagari, S. R. (1994). Uninsured idiosyncratic risk and aggregate saving. Quarterly Journal of Economics 109(3), 659-684.

Alvarez, F. and M. Veracierto (2001). Severance payments in an economy with frictions. Journal of Monetary Economics 47(3), 477-498.

Attanasio, O. P. (1999). Consumption. In J. B. Taylor and M. Woodford (Eds.), Handbook of Macroeconomics, Volume 1, Chapter 11. Amsterdam: North-Holland.

Attanasio, O. P., S. Kitao, and G. L. Violante (2011). Financing Medicare: A general equilibrium analysis. In J. Shoven (Ed.), Demography and the Economy, Chapter 9, pp. 333-370. Chicago: University of Chicago Press.

Auerbach, A. J. and L. J. Kotlikoff (1987). Dynamic Fiscal Policy. Cambridge: Cambridge University Press.

Autor, D. H. and M. G. Duggan (2010). Supporting work: A proposal for modernizing the u.s. disability insurance system. Center for American Progress and The Hamilton Project.

Bell, F. C. and M. L. Miller (2005). Life tables for the United States social security area 1900-2100. Office of the Chief Actuary, Social Security Administration.

Benitez-Sílva, H., M. Buchinsky, and J. Rust (2011). Induced entry effects of a $\$ 1$ for $\$ 2$ offset in SSDI benefits. Working Paper.

Bewley, T. F. (1986). Stationary monetary equilibrium with a continuum of independently fluctuating consumers. In W. Hildenbrand and A. Mas-Colell (Eds.), Contributions to Mathematical Economics in Honor of Gerald Debreu, pp. 79-102. Amsterdam: North-Holland.

Blanchard, O. J. (1985). Debt, deficits, and finite horizons. Journal of Political Economy $93(2), 223-247$.

Blundell, R. and T. MaCurdy (1999). Labor supply: A review of alternative approaches. In O. C. Ashenfelter and D. Card (Eds.), Handbook of Labor Economics, Volume 3, Chapter 27, pp. 1559-1695. Amsterdam: North-Holland.

Cagetti, M. and M. De Nardi (2009). Estate taxation, entrepreneurship, and wealth. American Economic Review $99(1), 85111$.

De Nardi, M., E. French, and J. B. Jones (2010). Why do the elderly save? The role of medical expenses. Journal of Political Economy 118(1), 39-75.

French, E. (2005). The effects of health, wealth, and wages on labour supply and retirement behaviour. Review of Economic Studies 72(2), 395-427. 
French, E. and J. B. Jones (2011). The effects of health insurance and self-insurance on retirement behavior. Econometrica 79 (3), 693-732.

Gertler, M. (1999). Government debt and social security in a life-cycle economy. Carnegie-Rochester Conference Series on Public Policy 50(1), 61-110.

Hsu, M. (2012). Health insurance and precautionary saving a structural analysis. Review of Economic Dynamics. forthcoming.

Hubbard, R. G., J. Skinner, and S. P. Zeldes (1995). Precautionary saving and social insurance. Journal of Political Economy 103(2), 360-399.

Huggett, M. (1993). The risk-free rate in heterogeneous-agent incomplete-insurance economies. Journal of Economic Dynamics and Control 17(5-6), 953-969.

İmrohoroğlu, S. and S. Kitao (2012). Social security reforms: Benefit claiming, labor force participation and long-run sustainability. American Economic Journal: Macroeconomics 4(3), 96-127.

Jacobson, L. S., R. J. LaLonde, and D. G. Sullivan (1993). Earnings losses of displaced workers. American Economic Review 83(4), 685-709.

Jeske, K. and S. Kitao (2009). U.S. tax policy and health insurance demand: Can a regressive policy improve welfare? Journal of Monetary Economics 56(2), 210-221.

Keane, M. P. and K. I. Wolpin (1997). The career decisions of young men. Journal of Political Economy 105(3), 473-522.

Kopecky, K. A. and T. Koreshkova (2009). The impact of medical and nursing home expenses on savings and welfare. Working Paper.

Low, H., C. Meghir, and L. Pistaferri (2010). Wage risk and employment risk over the life cycle. American Economic Review 100(4), 1432-1467.

Low, H. and L. Pistaferri (2011). Disability risk, disability insurance and life cycle behavior. Working paper.

Mendoza, E. G., A. Razin, and L. L. Tesar (1994). Effective tax rates in macroeconomics: Cross-country estimates of tax rates on factor incomes and consumption. Journal of Monetary Economics 34 (3), 297-323.

Palumbo, M. G. (1999). Uncertain medical expenses and precautionary saving near the end of the life cycle. Review of Economic Studies 66 (2), 395-421.

Pavoni, N. and G. L. Violante (2007). Optimal welfare-to-work programs. Review of Economic Studies 74(1), 283-318.

Social Security Administration (2007). Annual statistical report on the social security disability insurance program.

Yaari, M. E. (1965). Uncertain lifetime, life insurance, and the theory of the consumer. Review of Economic Studies 32(2), 137-150. 